\title{
The effect of RNA on the operant conditioned behavior of white rats'
}

\author{
LESLIE SOLYOM, CLAUDE BEAULIEU AND HILDEGARD E. ENESCO
}

ALLAN MEMORIAL INSTITUTE, MCGILL UNIVERSITY

This study was undertaken to determine whether exogenous RNA or its hydrolyzed components affect learning of an operant response. Three groups of 10 animals each were injected with (a) $160 \mathrm{mg} / \mathrm{kg}$ RNA, (b) $160 \mathrm{mg} / \mathrm{kg}$ hydrolyzed RNA, and (c) $0.5 \mathrm{cc}$ normal saline respectively. Only whole RNA facilitates acquisition of a bar-pressing response.

The purpose of this study is to investigate the effects of whole ribonucleic acid (RNA) on instrumental conditioning and to compare its effects with those of hydrolyzed RNA.

Previous investigations have shown that RNA administration seems to facilitate retention in senile patients (Cameron, 1958), and learning of an avoidance response in rats (Cook et al, 1963). On the basis of this evidence, it is predicted that RNAtreated animals will learn an operant response faster than saline control animals.

Other evidence indicates that exogenous RNA is rapidly broken down by the body and may contribute to the available RNA precursor pool (Roll et al, 1949; Sved, 1965). If this is so, it can then be predicted that hydrolyzed RNA would have the same effect as whole RNA on instrumental conditioning.

\section{EXPERIMENT I}

\section{Method}

Twenty female albino rats were used: four animals in the saline group and eight in each of the experimental groups.

Programming, stimulus presentation and recording were done automatically by two independent standard (Foringer) operant conditioning units. Both cumulative records and response counts were obtained.

Acquisition of bar-pressing behavior was carried out by the use of the master training technique, developed by Corson (in preparation). This consists of placing the naive water-deprived animal for fixed periods in the Skinner box along with another animal-the masterwho has previously learned bar-pressing. Throughout the master training, reinforcement is programmed in a 1:1 fixed ratio (continuous reinforcement), using $0.12 \mathrm{cc}$ of water as reinforcement. Care was taken to see that all masters had an equal number of pupils taken from all groups.

Immediately subsequent to reaching criterion in master training, all animals were subjected to three days of CRF training, followed by five days of variable interval (VI) training, the average inter-reinforcement interval being 1-1/2 min. The final phase of this experiment consisted of five days of extinction of bar-pressing, starting immediately after completion of VI training.

Immediately at the end of each daily training session, the animal was given water for $1 / 2 \mathrm{hr}$, thus making for a 23-hr. deprivation schedule.

I.P. injections of $160 \mathrm{mg} / \mathrm{kg}$ RNA or hydrolyzed RNA were given after all animals were testedbetween 5 and 6 p.m. Injections were started one month prior to onset of the experiment and were continued throughout its entire course.

Commercial yeast RNA was obtained from Pabst Laboratories; it was injected in $10 \%$ neutral solution. To produce hydrolyzed RNA from the same starting material, an alkaline hydrolysis procedure was adapted from Roll et al (1949).

\section{Results}

The mean number of bar-presses for each group during the three days of CRF training was analyzed by Duncan's Multiple Range Test, which revealed that the mean number of bar-presses of the hydrolyzed RNA group for the three combined days was significantly greater than that of the saline group $(p<.05)$, while the whole RNA group was not different from either the saline group or the hydrolyzed RNA group.

Analysis of variance on the data during VI training, the means of which are shown in Fig. 1, also failed to reveal any significance. In spite of this, Duncan's Multiple Range Test revealed that the mean number of bar-presses made by the whole RNA group over the five days of VI training was significantlygreater than that of either the hydrolyzed RNA or the saline groups $(p<.01)$, these latter not differing from each other.

The results obtained during extinction are illustrated in Fig. 2, and the group-by-days analysis of variance on these data shows that there is a significant group effect $(p<.05)$. The significant group effect was further analyzed by means of Duncan's Multiple Range Test, which showed, once again, that the whole RNA group

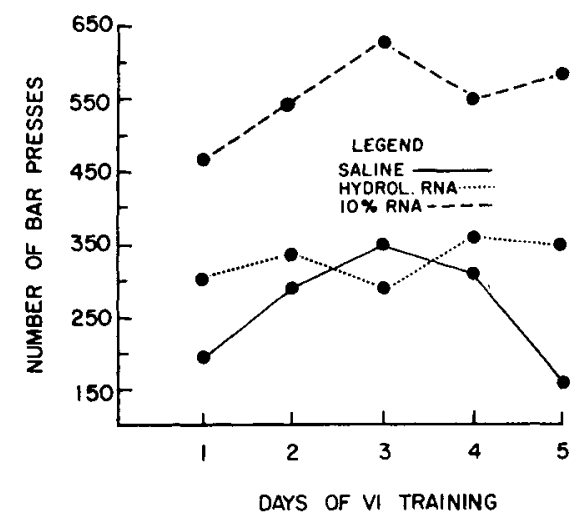

Fig. 1. Number of bar presses during 5 days VI reinforcement. Experiment I. 


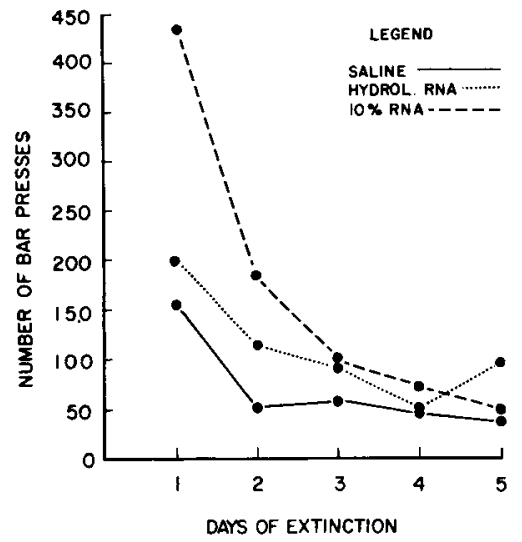

Fig. 2. Number of bar presses during 5 days extinction of bar pressing.

pressed significantly more during the five days of extinction period than either the hydrolyzed RNA or the saline groups $(p<.05)$, these latter not differing from each other. Inspection of Fig. 2 shows that the significant group-by-days interaction $(p<.05)$ is due to a more rapid decline of response rate in the whole RNA group than in either of the other groups.

In summary, it was found that the hydrolyzed RNA group bar-pressed more than the saline group during CRF training, while the whole RNA group pressed more than either the saline or hydrolyzed RNA groups during both VI training and extinction.

\section{EXPERIMENT II}

Failure to find a group effect during VI training in Experiment I may have been due to an insufficient amount of training. It was, therefore, decided to retrain the animals under the same VI schedule, but for a longer time.

\section{Method}

The animals in this experiment were those included in the final analysis of Experiment $I$, except for the addition of two animals in the saline group who had originally not met criterion during master training, but were subjected to the entire procedure of Experiment I.

For 22 successive days, all animals spent a 1/2-hr. daily period in a soundproof Skinner box where they had to bar-press for water reinforcement. A 1-1/2

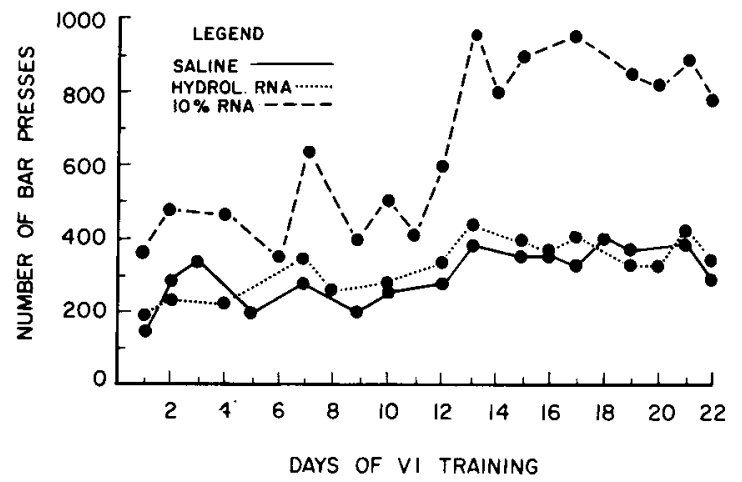

Fig. 3. Number of bar presses during 22 days VI reinforcement. Experiment II. min. variable interval (VI) was used.

Results

Figure 3 shows the mean number of bar-presses for each of the three groups over the 22 days of VI training.

A group-by-days analysis of variance on these data reveals both a significant group effect $(p<.05)$ and trial effect $(p<.001)$, but no significant interaction. The whole RNA group pressed considerably more than either the hydrolyzed RNA of the saline groups, which do not differ from one another.

\section{DISCUSSION}

The results when analyzed by Duncan's Multiple Range Test show that RNA-injected animals barpressed at a significantly higher rate than the hydrolyzed RNA or saline injected rats in all phases of the experiment, except during CRF training. Analysis of variance when applied only to the results of Experiment I reveals no significant differences between any of the groups. This may be due to an insufficient number of experimental trials. Indeed, in Experiment II, where the animals were tested for a much longer period, the analysis of variance confirms the results obtained with Duncan's Range Test.

The conclusion that can be drawn at this time is that RNA injections produce an enhanced rate of barpressing under a VI schedule of water reinforcement. This experiment did not attempt to clarify whether this result should be attributed to increased activity, increased learning, or increased motivation. It has been reported that RNA injections do not increase the activity of rats in an open field (Corson \& Enesco, 1966), and present research in this laboratory indicates that RNA-injected animals do not have greater water requirements than control animals (Beaulieu, unpublished data). Thus, by process of elimination, our results could be taken as suggestive evidence that RNA injections affect learning of a bar pressing response.

The fact that hydrolyzed RNA does not differ significantly from the saline group in most phases of the experiment points to the conclusion that the whole RNA molecule, not its breakdown products, must be injected to produce the observed effects.

\section{References}

Cameron, D. E. The use of nucleic acid in aged patients with memory impairment. Amer. J. Psychiat., 1958, 114, 943.

Cook, L., Davidson, A. B., Davis, D. J., Green, H., \& Fellows, E, J. Ribonucleic acid: effect on conditioned behaviour in rats. Science, 1963, 141, 268-269.

Corson, J. A. Observational learning of a bar-pressing response, in preparation.

Corson, J. A., \& Enesco, H. E. Some effects of injections of ribonucleic acid. Psychon. Sci., 1966, 5, 217-218.

Roll, P. M., Brown, G. B., DiCarlo, F. J., \& Schultz, A. S. The metabolism of yeast nucleic acid in the rat. J. Biol. Chem., $1949,180,333-340$.

Sved, $\mathbf{S}$. The metabolism of exogenous ribonucleic acid injected into mice. Canad. J. Biochem., 1965, 43, 949-958.

Note

1. This study was supported by Dominion-Provincial Mental Health Grant No. 604-7-499. 